\title{
Influences of Urban Expansion on Urban Heat Island in Beijing during 1989-2010
}

\author{
Zhi Qiao, ${ }^{1}$ Guangjin Tian, ${ }^{1}$ Lixiao Zhang, ${ }^{1}$ and Xinliang $X u^{2}$ \\ ${ }^{1}$ State Key Laboratory of Water Environment Simulation, School of Environment, Beijing Normal University, \\ No. 19 Xinjiekouwai Street, Haidian District, Beijing 100875, China \\ ${ }^{2}$ State Key Laboratory of Resources and Environmental Information Systems, Institute of Geographical Sciences and \\ Natural Resources Research, Chinese Academy of Sciences, No. A11 Datun Road, Chaoyang District, Beijing 100101, China
}

Correspondence should be addressed to Guangjin Tian; tianguangjin@bnu.edu.cn

Received 15 January 2014; Accepted 7 March 2014; Published 31 March 2014

Academic Editor: Dong Jiang

Copyright (C) 2014 Zhi Qiao et al. This is an open access article distributed under the Creative Commons Attribution License, which permits unrestricted use, distribution, and reproduction in any medium, provided the original work is properly cited.

Beijing has experienced rapid urbanization and associated urban heat island (UHI) effects. This study aimed at analyzing the impact of urban form on UHI in Beijing using TM/ETM images between 1989 and 2010. Spatial analysis was proposed to explore the relationships between area, compactness ratio, the gravity centers of urban land, and UHI. The UHI in Beijing spatially represented a "NE-SW" spindle. The land surface temperature (LST) was higher in south than in north. Urban Heat Island Ratio Index (URI) was well interrelated with urban land area in different zones. Under the similar urban land area condition, UHI and compactness ratio of urban land were in positive correlation. The moving direction of the UHI gravity center was basically in agreement with urban land sprawl. The encroachment of urban land on suburban land is the leading source of UHI effect. The results suggest that urban design based on urban form would be effective for regulating the thermal environment.

\section{Introduction}

With the background of rapid urbanization, the population living in urban areas is forecasted to be five billion by 2030 [1]. Numerous modifications of land surface will occur as an accumulating number of people migrate into metropolitan areas [2]. The modification of land surface will result in urban climate change. There is a remarkable phenomenon for urban climates that the temperatures of urban land and their surrounding rural regions are different. The distinct differences in the temperature are referred to as urban heat island (UHI) $[3,4]$. The UHI would significantly affect the human living conditions and increase energy consumption and atmospheric pollution [5]. The acceleration of urbanization, such as increased impervious surfaces and population density, would increase the UHI [6].

Numerous studies have focused on the impact of the urban form on urban environment. Urban form, which is a term that broadly refers to the layout and design of a city, affects ecological and environmental quality through the composition and fragmentation of land pattern, the water and energy consumption, and air movement [7-11]. Oke [12] stated urban size as a main factor in the UHI development. Declines in thermal inertia and the vegetation index because of the encroachment of urban land constrain evaporation consequently reduce the loss of heat by latent heat flux [13]. The reduction of wind speeds [14] and sky-view factors [5, 7], higher anthropogenic heat release $[5,7,14]$, increased energy demands, and congestion of transportation networks [11] resulting from urbanization will further aggravate UHI effect. However, urban growth is an inevitable tendency following the people migrating into metropolitan areas. "Good urban form" would mitigate the deterioration of the metropolitan environment $[15,16]$ as recent discussions of "urban sprawl" in the United States and the "compact city" in Europe [1719]. The relationships between urban form and transportation energy consumption have been examined to reduce $\mathrm{CO}_{2}$ emissions [20-22]. Marquez and Smith [23] established a land use - transport - environment model linking urban form to improve air quality. So far, no detailed study has been made on the theoretical achievements and practical applications in the relationship between urban form and urban thermal 


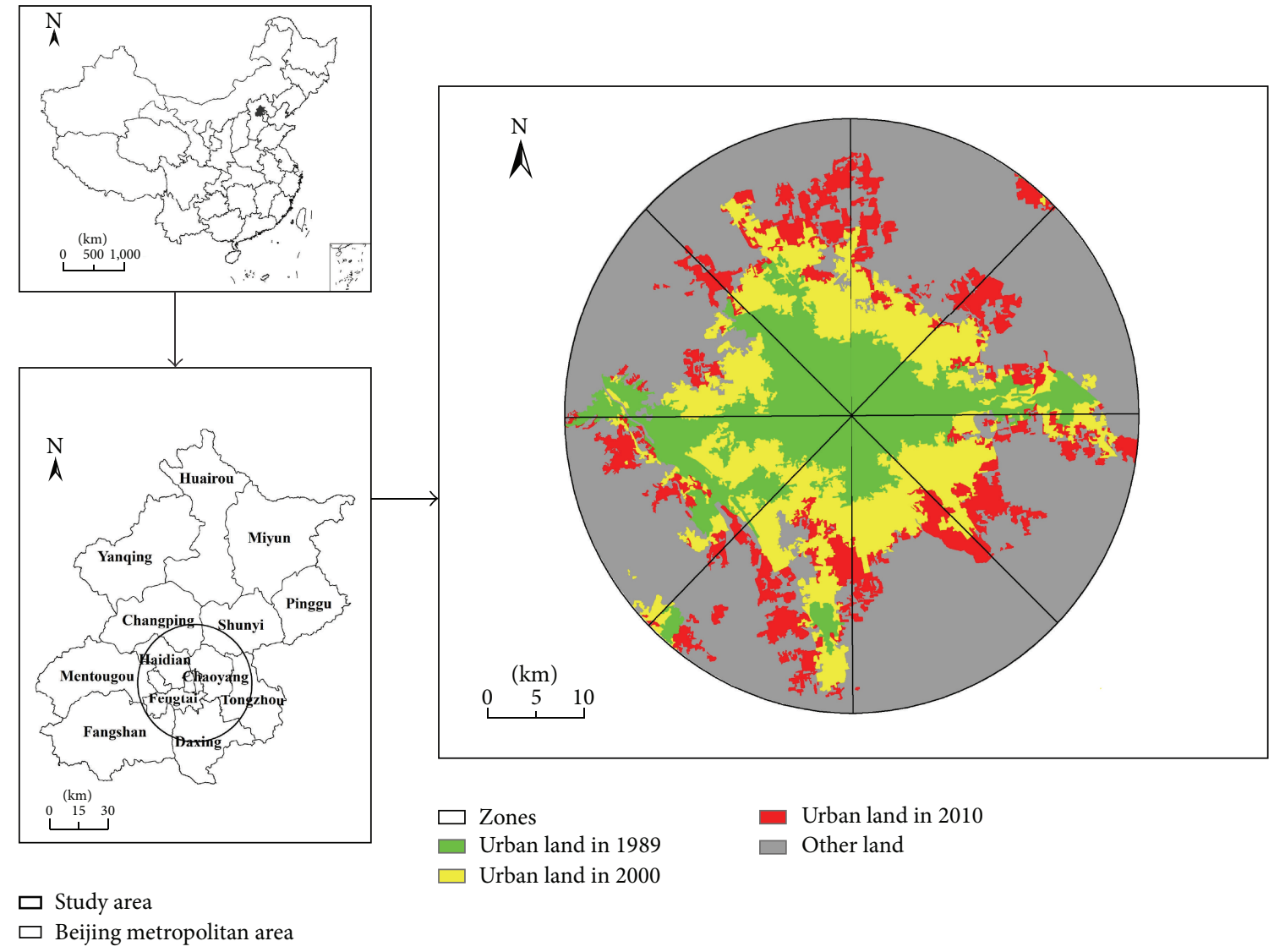

FIGURE 1: The spatial distribution of urban land in Beijing during 1989-2010.

environment in Beijing. The study focused on the following. (1) What were temporal-spatial characteristics of urban form and UHI during the period of 1989-2010? (2) How has urban form impacted UHI effect in Beijing?

To characterize urban growth, form, and spatial structure, various indicators such as density, compactness, complexity, and circularity ratios are used to represent urban characteristics [24]. The zonal strategy also provides us with a scientific method of measuring spatial geographic information for urban agglomeration [25-27]. Similarly to urban form, the measurement of urban heat island also has been the focus of a large number of studies, and for which several indicators have been assigned $[9,28-30]$. Satellite observation provides a quantitative measurement of urban sprawl and UHI. Advanced Very High Resolution Radiometer (AVHRR) data from the National Oceanic and Atmospheric Administration (NOAA) [31, 32], Thermal infrared (TIR) data from the Thematic Mapper (TM) and Enhanced Thematic Mapper Plus (ETM) [33, 34], Moderate-Resolution Imaging Spectroradiometer (MODIS) LST products have been successively utilized to study the UHI effect [30]. The present study analyzed LST from TM/ETM collected in 1989, 2000, and 2010, respectively. In addition, Landsat TM images were analyzed to retrieve land use types.

\section{Study Area and Data Sources}

2.1. Study Area. Beijing, the capital of the People's Republic of China, extends approximately $1^{\circ} 37^{\prime}$ latitudinally $\left(39^{\circ} 26^{\prime}-41^{\circ} 03^{\prime} \mathrm{N}\right)$ and $2^{\circ} 05^{\prime}$ longitudinally $\left(115^{\circ} 25^{\prime}-117^{\circ} 30^{\prime} \mathrm{E}\right)$. It covers fourteen districts and two counties, and the total area is approximately $16410 \mathrm{~km}^{2}$ [35] (Figure 1). The city has a subhumid warm temperate continental monsoon climate and four distinct seasons, with a cold and windy winter, and a hot and humid summer. Beijing has experienced the rapid urbanization process. The permanent population was 10.75 million in 1989 and reached up to 19.62 million in 2010. In a similar way, Gross Domestic Product (GDP) increased from 45.6 billion to 1411.3 billion with approximate 30 times increase during 1989-2010 [35]. Recently, environmental problems (e.g., UHI, sand and dust storms, and pollution haze) resulting from rapid population and economic growth have negatively affected the quality and comfort of urban living [36].

Environmental problems, especially UHI in Beijing, have drawn international attention. Zhang et al. [37] reported that the average UHI was approximately $4-6^{\circ} \mathrm{C}$ when using a suburban area in the northwestern region as the rural baseline and $8-10^{\circ} \mathrm{C}$ when using the outer suburban area in the same region. Warmer temperatures even delay the timing of fall foliage vacation [38]. With the diversified and rapid development of the economy and urban society, urban sprawl in Beijing will likely expand and the UHI effect will become more severe [29].

2.2. Data Sources. The land use datasets were provided by the Institute of Geographical Sciences and Natural Resources 
Research, Chinese Academy of Sciences. The study collected three periods of land use datasets, that is, 1989, 2000, and 2010. To retrieve the land cover types, Landsat TM images were chosen and radiantly corrected. The visual interpretation was conducted on the false color composites $(\mathrm{R} / \mathrm{G} / \mathrm{B}=$ Band 5/4/3) of TM/ETM+ images. There were six aggregated classes of land use: cropland, forest, grassland, water bodies, built-up land, and bare land. These classes were further divided into 25 land use classes. The built-up land contains urban land, rural residential land, and industrial and mining sites. The average interpretation accuracies were $92.9 \%$ for land use and $97.6 \%$ for the detection of changes in land cover. For cropland, the accuracy was $94.9 \%$. The built-up area had the highest accuracy of $96.3 \%$. For forest and grassland, the accuracies were $90.1 \%$ and $88.1 \%$, respectively [39]. In addition, three high-quality (cloud-free) TM/ETM images on 14 August, 1989, 10 August, 2000, and 8 August, 2010 were applied to retrieve LST, respectively.

\section{Methods}

\subsection{The Measures of Urban Form}

3.1.1. Urban Form Measurement Indices. The compactness ratio of urban outer contour is an important concept reflecting the urban form [27, 40-42], and it is computed as follows:

$$
\mathrm{BCI}=2 \frac{\sqrt{\pi A}}{P},
$$

where BCI is the compactness ratio of urban land, $A$ is the area of urban land, and $P$ is the perimeter of urban contour. $\mathrm{BCI}$ ranges from 0 to 1 ; a higher value indicates a more compacted shape and a value closer to 1 indicates that the shape is closer to a circle, and vice versa. A circle is the most compact shape, and thus the compactness ratio of a long and narrow shape is far smaller than 1.

In general, if urban land expansion changes in the infilling way, the concavity of urban edges will decrease because the urban internal gaps are gradually filled up, and as a result, the urban outer contour form tends to be more compact. If the urban land expansion changes in the edge-expansion way, the urban form tends to be incompact. However, the debate over whether a compact urban form is best for urban thermal environment had lasted for a long history [43, 44]. The heat sources in low-density spreading urban area are relatively dispersed, but the increased fuel consumption by vehicles produces more anthropogenic heat. However, the newly large-area buildings will occupy more green land, increasing the area of impervious surface and enhancing UHI effect.

3.1.2. Urban Land Expansion Measurement Indices. The most common method to describe the heterogeneous of urban land expansion is to comparatively analyze the differences of urban expanding speeds at different directions (Figure 1). The method visually and concisely sketches the spatial form of urban expansion and discriminates the spatial heterogeneous in different zones. In this paper, we designed a $30 \mathrm{~km}$ buffer around the city center, which could cover all urban builtup land. We also studied the urban spatial heterogeneous by dividing the buffer zones into eight quadrants.

The speed and intensity of urban land expansion can be used to analyze and describe the land expansion status at all directions in the urban built-up land and to compare the extending intensity, speeds, and trends of urban land in all study areas at different periods $[45,46]$. The two indices are expressed as

$$
\begin{gathered}
M_{\mathrm{ue}}=\frac{\Delta U_{i j}}{\Delta t_{j} \times \mathrm{ULA}_{i j}} \times 100 \% \\
I_{\mathrm{ue}}=\frac{\Delta U_{i j}}{\Delta t_{j} \times \mathrm{TLA}_{i j}} \times 100 \%,
\end{gathered}
$$

where $M_{\mathrm{ue}}$ is the expanding speed index, $I_{\mathrm{ue}}$ is the expanding intensity index, $\Delta U_{i j}$ is the expansion area of urban land in study area $i$ (e.g., a zone at certain direction) at period $j, \Delta t_{j}$ is the time span, $\mathrm{ULA}_{i j}$ is the total area of urban land in study area $i$ at early period $j$, and $\operatorname{TLA}_{i j}$ is the total area of urban land in study area $i$.

The expanding speed indicates the annual growing rate of urban land at different stages during a whole study period and represents the overall trend of different types of urban land expansion at all stages. The expanding intensity index essentially is used to standardize the annual average expanding speeds of all spatial units, and thus the expanding speeds at different periods can be compared [47].

The centre of gravity is an important indicator describing the spatial distribution transition of a geographic subject $[48,49]$. Center of gravity reflects the spatial orientation of a spatial element and the overall heterogeneous and "highdensity" parts of a type of land use, and its dynamic transition reflects the overall transfer trajectory of the distribution of spatial elements. The gravity center of urban land is an important spatial index related to urban development and has high applicable value in urban development decisionmaking.

For multiple geographical objects, the coordinates of gravity center can be computed as follows:

$$
\begin{aligned}
& X_{t}=\frac{\sum_{i=1}^{n}\left(C_{t i} \times X_{i}\right)}{\sum_{i=1}^{n} C_{t i}} \\
& Y_{t}=\frac{\sum_{i=1}^{n}\left(C_{t i} \times Y_{i}\right)}{\sum_{i=1}^{n} C_{t i}},
\end{aligned}
$$

where $X_{t}$ and $Y_{t}$ are the gravity centers of urban land at time $t, X_{i}$ and $Y_{i}$ are the coordinates of geometric center of urban land in block $I$, and $C_{t i}$ is the area of block $i$.

We further put forward two variables: gravity center transfer distance $(L)$ and gravity center transfer angle $(\alpha)$. The transfer distance reflects the homogeneous degree of urban land between different periods, and the transfer direction indicates the "high- density" parts of urban land $[48,49]$ :

$$
L_{t+1}=\sqrt{\left(x_{t+1}-x_{t}\right)^{2}+\left(y_{t+1}-y_{t}\right)^{2}} \text {, }
$$


where $L_{t+1}$ is the gravity center transfer distance of urban land from period $t$ to period $t+1$ :

$$
\alpha_{t+1}= \begin{cases}\arctan \left(\frac{y_{t+1}-y_{t}}{x_{t+1}-x_{t}}\right), & x_{t+1} \geq x_{t}, \quad y_{t+1} \geq y_{t}, \\ \pi-\arctan \left(\frac{y_{t+1}-y_{t}}{x_{t+1}-x_{t}}\right), & x_{t+1}<x_{t}, y_{t+1} \geq y_{t}, \\ \pi+\arctan \left(\frac{y_{t+1}-y_{t}}{x_{t+1}-x_{t}}\right), & x_{t+1}<x_{t}, y_{t+1}<y_{t}, \\ 2 \pi+\arctan \left(\frac{y_{t+1}-y_{t}}{x_{t+1}-x_{t}}\right), & x_{t+1} \geq x_{t}, y_{t+1}<y_{t}\end{cases}
$$

where $\alpha_{t+1}$ is the angle between the transfer direction and the east direction from period $t$ to period $t+1$.

\subsection{The Spatiotemporal Pattern of LST}

3.2.1. The Retrieval of Brightness Temperature from the Landsat 5 TM Images. Chen et al. [50] proposed a two-step method to derive brightness temperature. First, the digital numbers (DNs) of band 6 are converted to radiation luminance $\left(R_{\mathrm{TM} 6}\right.$, $\left.\mathrm{m} \cdot \mathrm{W} \cdot \mathrm{cm}^{-2} \cdot \mathrm{sr}^{-1}\right)$ as follows:

$$
R_{\mathrm{TM} 6}=\frac{V}{255}\left(R_{\max }-R_{\min }\right)+R_{\min }
$$

where $V$ is the $\mathrm{DN}$ of band 6 , and $R_{\max }=1.896 \mathrm{~m} \cdot \mathrm{W} \cdot \mathrm{cm}^{-2}$. $\mathrm{sr}^{-1}, R_{\min }=0.1534 \mathrm{~m} \cdot \mathrm{W} \cdot \mathrm{cm}^{-2} \cdot \mathrm{sr}^{-1}$.

Then radiation luminance is converted to at-satellite brightness temperature in Kelvin, $T(K)$, as follows:

$$
T=\frac{K 1}{\ln \left(K 2 /\left(R_{\mathrm{TM} 6} / b\right)+1\right)},
$$

where $K 1=1260.56 \mathrm{~K}$ and $K 2=60.766\left(\mathrm{~m} \cdot \mathrm{W} \cdot \mathrm{cm}^{-2}\right.$. $\mathrm{sr}^{-1}$ ), which are prelaunch calibration constant, and $b$ is the effective spectral range, when the sensor's response is much more than $50 \%, b=1.239(\mu \mathrm{m})$.

\subsubsection{Retrieval of Brightness Temperature from Landsat 7} ETM+ Images. Landsat 7 ETM products were utilized for retrieving temperature in 2000 according to the User's Handbook. It is also simplified to two steps as follows.

First, the DNs of band 6 were converted to radiance as follows:

$$
R_{\mathrm{TM} 6}=\frac{L_{\text {max }}-L_{\text {min }}}{Q_{\text {cal max }}-Q_{\text {cal min }}} \times\left(Q_{\text {cal }}-Q_{\text {cal min }}\right)+L_{\text {min }},
$$

where the gain and offset can be obtained from the header file, $Q_{\text {cal min }}=1, Q_{\text {cal max }}=255, Q_{\text {cal }}=D N$, and $L_{\text {max }}$ and $L_{\text {min }}$ (also given in the header file) are the spectral radiances for band 6 at DNs 1 and 255 (i.e., $Q_{\text {cal min }}$ and $Q_{\text {cal max }}$ ), respectively.

Then the effective at-satellite temperature of the viewed Earth-atmosphere system under the assumption of uniform emissivity could be obtained from the above spectral radiance as follows:

$$
T=\frac{K 2}{\ln \left(K 1 / R_{\mathrm{TM} 6}+1\right)},
$$

where $T$ is the effective at-satellite brightness temperature in Kelvin, $K 1=666.09\left(\mathrm{~m} \cdot \mathrm{W} \cdot \mathrm{cm}^{-2} \cdot \mathrm{sr}^{-1}\right)$ and $K 2=1282.71 \mathrm{~K}$ are calibration constants, and $R_{\mathrm{TM}}$ is the spectral radiance in $\mathrm{m} \cdot \mathrm{W} \cdot \mathrm{cm}^{-2} \cdot \mathrm{sr}^{-1}$.

3.2.3. Retrieval of LST. The calculated radiant temperatures were corrected for emissivity by using the normalized differential vegetation index (NDVI). The study thresholds the NDVI images into two general vegetation and nonvegetation classes, and assigning emissivity values of 0.95 and 0.92 to them, respectively, produced emissivity images for each data [51]. Then, LST was calculated as below [33, 52-57]:

$$
T_{s}=\frac{T}{1+(\lambda T / \rho) \ln \varepsilon},
$$

where $\lambda=$ wavelength of radiance $=11.5 \mu \mathrm{m}, \rho=h c / \delta=$ $1.438 \times 10^{-2} \mathrm{mK}\left(h=\right.$ Planck's constant $=6.626 \times 10^{-24} \mathrm{Js}$, $c=$ velocity of light $=2.998 \times 10^{8} \mathrm{~m} / \mathrm{s}$, and $\delta=$ Boltzmann constant $\left.=1.38 \times 10^{-23} \mathrm{~J} / \mathrm{k}\right)$. Because of the importance of vegetation as a temperature controlling factor, the emissivity correction resulted in significant differentiation of classes and increased spatial detail comparable to those of reflective bands. Finally, the images were converted to Celsius.

3.2.4. The Calculation of Urban Heat Island Ratio Index (URI). In this paper, we aimed to study the spatiotemporal variation of UHI by using LST data inverted from remote sensing (RS) images at different periods. Then based on bright temperature normalization, we introduced URI to quantify UHI $[28,46]$.

UHI study focuses on the spatial relative intensity of LST. Conditions in surrounding rural areas also affect the magnitude of an UHI [58]. For example, Streutker [32] found that UHI intensity was inversely correlated with rural LST. RS images obtained from different periods only change the values of LST, rather than changing the spatial distribution of LSTs. Therefore, LSTs were normalized to compare the spatial distributions of LSTs at the three periods, and thereby the spatiotemporal pattern variations of UHI in Beijing between 1989 and 2010 were studied.

First, LSTs at different periods were normalized to be between 0 and 1 :

$$
T_{n i}=\frac{T_{s i}-T_{s \min }}{T_{s \max }-T_{s \min }},
$$

where $T_{n i}$ is the normalized value of pixel $i$; $T_{s i}$ is the LST of pixel $i ; T_{s \max }$ is the maximum LST in Beijing; and $T_{s \text { min }}$ is the minimum LST.

Then the normalized LSTs were classified by a density segmentation method into five thermodynamic levels: low, submedium, medium, subhigh, and high. Thereby, the distribution of LST levels in Beijing was characterized, and the area of each level could be calculated according to Table 1 .

Finally, URI was introduced to quantify the contribution rate of urban land to UHI $[28,46]$ :

$$
\mathrm{URI}=\frac{1}{100 m} \sum_{i=1}^{n} w_{i} p_{i}
$$


TABLE 1: The thresholds of different thermodynamic levels (unit: ${ }^{\circ} \mathrm{C}$ ).

\begin{tabular}{lccc}
\hline Level & 1989 & 2000 & 2010 \\
\hline Low & $21-23.46$ & $21-22.33$ & $21-23.82$ \\
Submedium & $23.46-24.75$ & $22.33-23.35$ & $23.82-25.85$ \\
Medium & $24.75-25.60$ & $23.35-24.87$ & $25.85-27.10$ \\
Subhigh & $25.60-26.87$ & $24.87-26.85$ & $27.10-28.91$ \\
High & $26.87-30$ & $26.85-31$ & $28.91-32$ \\
\hline
\end{tabular}

where $m$ is number of normalized temperature levels; $i$ is the level value of temperatures higher than rural areas; $n$ is number of higher temperature levels mainly occurring in urban areas; $w$ denotes weighted value using the value of correspond level $i$; and $p$ is the area percentage of level $i$. Essentially, URI is obtained by computing the ratio of UHI area to urban land with the consideration of weighted values of each temperature level. It reflects the development degree of UHI in built-up land. A larger URI indicates more severe UHI effect.

\section{Results}

4.1. The Spatiotemporal Pattern of Urban Form. Urban land expansion is a basic characteristic of urban form evolution. The urban land increased by $775.82 \mathrm{~km}^{2}$ at a rate of $184.31 \%$ between 1989 and 2010 (Table 2). Specifically, the urban land increased by $469.32 \mathrm{~km}^{2}$ during $1989-2000$ and by $306.50 \mathrm{~km}^{2}$ during 2000-2010, respectively. The expanding intensity of urban land $\left(I_{\mathrm{ue}}\right)$ decreased from 1.51 during 1989-2000 to 1.08 during 2000-2010, indicating the slowdown of expanding speed. Regarding urban form, the urban land was distributed like an "E-W" axis in 1989. The urban land in north of the axis was highly compacted, indicating high clustering degree; the urban land in south of the axis was less compacted, indicating scattered distribution. From 1989 to 2010, the newly urban land sprawled north- and southwards along the axis, and thus the compactness ratio of urban land slightly decreased, showing an overall edge-expansion mode (Figures 2 and 3).

In 1989, the urban lands were concentrated in southwest and west, for example, Xicheng, Fengtai, and Shijingshan Districts, accounting for $41.38 \%$ of total built-up land in the study area. The area of urban land in northeast zone was $70.17 \mathrm{~km}^{2}$. The urban land in the three zones expanded in an infilling way, and compactness index (BCIs) all increased during 1989-2000. Especially, BCI increased from 0.17 to 0.25 in the southwest zone, which was attributed to the large area of newly urban land in Fengtai District and the continuous infilling expansion of urban land in Xicheng, Haidian, and Shijingshan districts. BCIs in other zones slightly decreased during the same period. These results indicated that the newly urban land were spreading outward, and especially in the south and northwest zones, the expanding intensity $\left(I_{\mathrm{ue}}\right)$ reached 2.17 and 1.84, respectively. However the BCIs did not change obviously. Urban land in southeast zone also expanded apparently, and the expanding intensity reached 1.63 , but BCI dropped in the same zone. The expanding

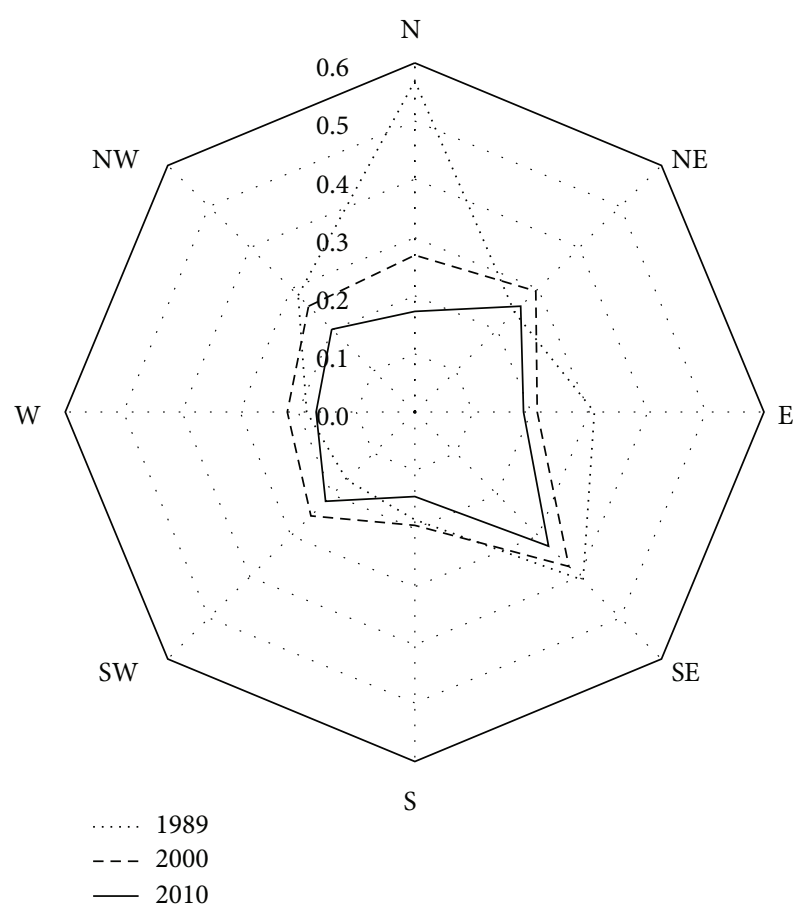

FIgURE 2: Compactness ratio index.

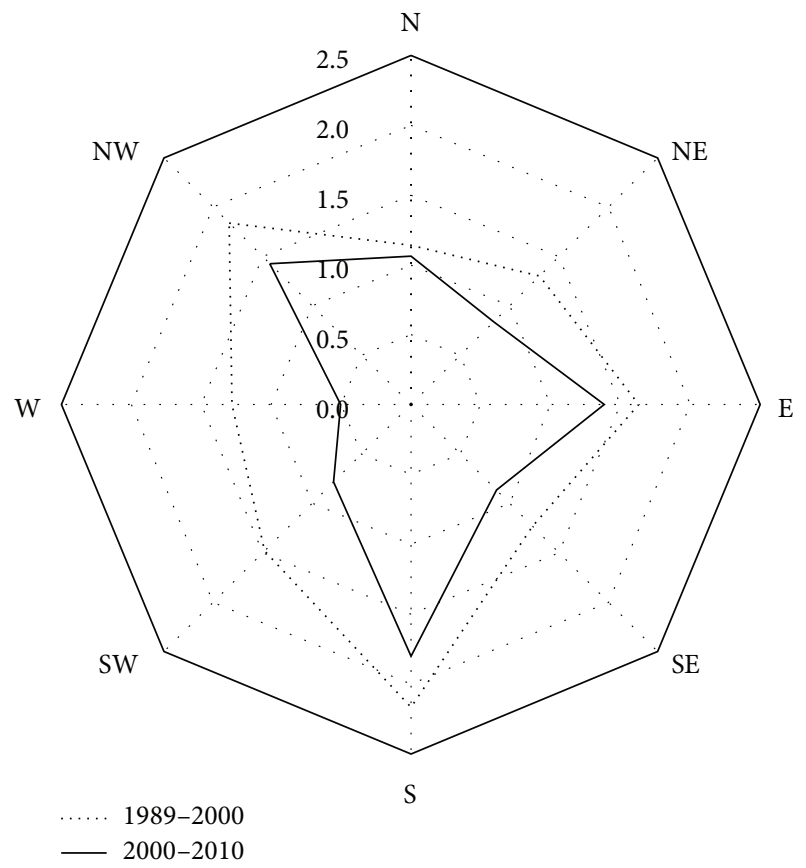

Figure 3: Urban land expanding intensity.

speed and the compactness ratio of urban land slightly decreased during 2000-2010, and the urban land was more decentralized. The urban expansion still was apparent in the south, northwest, and southeast zones. Especially, the area of urban land was $185.48 \mathrm{~km}^{2}$, a 4-fold increase more than 1989 in Fengtai and Daxing Districts. 
TABLE 2: The characteristics of urban land expansion in Beijing during 1989-2010 (unit: area-km²).

\begin{tabular}{lcccccccccc}
\hline \multirow{2}{*}{ Zone } & \multicolumn{2}{c}{1989} & \multicolumn{2}{c}{2000} & \multicolumn{2}{c}{2010} & \multicolumn{2}{c}{$1989-2000$} & \multicolumn{2}{c}{$2000-2010$} \\
& Area & BCI & Area & BCI & Area & BCI & $M_{\text {ue }}$ & $I_{\text {ue }}$ & $M_{\text {ue }}$ & $I_{\text {ue }}$ \\
\hline N & 27.25 & 0.57 & 71.98 & 0.27 & 109.93 & 0.17 & 14.92 & 1.14 & 5.27 \\
NE & 70.17 & 0.24 & 120.25 & 0.29 & 149.50 & 0.26 & 6.49 & 1.30 & 2.43 & 0.84 \\
E & 30.82 & 0.31 & 93.53 & 0.21 & 141.87 & 0.19 & 18.50 & 1.63 & 5.17 & 1.38 \\
SE & 23.84 & 0.41 & 72.19 & 0.37 & 103.09 & 0.33 & 18.44 & 1.23 & 4.28 & 0.87 \\
S & 36.07 & 0.19 & 121.20 & 0.19 & 185.48 & 0.14 & 21.45 & 2.17 & 5.30 & 1.80 \\
SW & 102.03 & 0.17 & 159.00 & 0.25 & 186.34 & 0.22 & 5.08 & 1.48 & 1.72 \\
W & 72.13 & 0.19 & 121.35 & 0.22 & 138.86 & 0.17 & 6.20 & 1.28 & 1.44 \\
NW & 58.60 & 0.28 & 130.75 & 0.26 & 181.67 & 0.20 & 11.19 & 1.84 & 3.89 & 0.50 \\
Built up area & 420.93 & 0.11 & 890.25 & 0.11 & 1196.75 & 0.09 & 10.14 & 1.51 & 3.44 \\
\hline
\end{tabular}

TABLE 3: The LST and URI of urban land in Beijing between 1989 and 2010.

\begin{tabular}{|c|c|c|c|c|c|c|}
\hline \multirow{2}{*}{ Zone } & \multicolumn{2}{|c|}{1989} & \multicolumn{2}{|c|}{2000} & \multicolumn{2}{|c|}{2010} \\
\hline & $\operatorname{LST}\left({ }^{\circ} \mathrm{C}\right)$ & URI & $\operatorname{LST}\left({ }^{\circ} \mathrm{C}\right)$ & URI & LST $\left({ }^{\circ} \mathrm{C}\right)$ & URI \\
\hline $\mathrm{N}$ & 26.73 & 0.06 & 27.47 & 0.18 & 27.83 & 0.23 \\
\hline $\mathrm{NE}$ & 26.45 & 0.16 & 27.22 & 0.30 & 27.83 & 0.32 \\
\hline $\mathrm{E}$ & 27.32 & 0.08 & 27.37 & 0.23 & 28.46 & 0.31 \\
\hline SE & 27.57 & 0.06 & 27.71 & 0.18 & 28.43 & 0.23 \\
\hline S & 27.56 & 0.09 & 27.41 & 0.30 & 28.35 & 0.41 \\
\hline SW & 26.85 & 0.25 & 27.70 & 0.41 & 28.54 & 0.44 \\
\hline W & 26.12 & 0.15 & 27.44 & 0.31 & 27.99 & 0.31 \\
\hline NW & 26.85 & 0.14 & 27.10 & 0.31 & 27.87 & 0.38 \\
\hline Beijing & 26.78 & 0.12 & 27.39 & 0.27 & 28.26 & 0.30 \\
\hline
\end{tabular}

4.2. The Spatiotemporal Pattern of LST. The LSTs in Beijing between 1989 and 2010 were quantitatively retrieved from TM/ETM data, and their spatiotemporal patterns were further analyzed (Figure 4). In general, the LSTs and URIs of urban land increased from 1989 to 2010, heat island areas expanded, and the UHI intensity resulting from urban expansion obviously increased (Table 3 ). LSTs in urban land were higher in south than in north in 1989, mainly because there were more industrial lands in the south of Beijing. However, the spatial distribution became less obvious along with urban expansion during 1989-2000, because some largescale energy-intensive factories were completely moved out and the released industrial heat sources were reduced.

UHIs in 1989 distributed like an "NE-SW" spindle, as URI in the southwest zone where URI reached up to 0.25 was obviously higher than in other zones (Figure 5), because largescale energy-intensive enterprises including Shoudu Iron and Steel Company and some thermal power plants were located in Shijingshan district. They discharged abundant heat to cause elevated temperature in atmosphere and land surface. URI was also high in the northeast zone $(U R I=0.16)$ and UHI effect was more severe than the adjacent zones, which mainly were associated with the Beijing Capital International Airport in Shunyi district. URIs increased largely and heat island area expanded obviously between 1989 and 2000. However UHIs were still distributed like an "NE-SW" spindle in the southwest and northeast zones. URIs increased significantly and raised above 0.3 in the west, south, and northwest zones.
Especially the increase of URI was most obvious in the south zone, which was associated with the highest urban expanding intensity. The urban-rural transition belt of the main urban area to Tongzhou/Fangshan districts has clearly manifested UHI characteristics.

URIs in all zones further increased and UHI was more severe in Beijing between 2000 and 2010. URI was still highest in the southwest zone (URI $=0.44)$, followed by the south zone (URI $=0.41)$. Noticeably, URI in the northwest zone increased rapidly to 0.38 , because of the tremendous expansion of urban land. A mountain of high-tech industry areas and large-scale residential areas emerged and gradually became new heat island centers, such as Zhongguancun, Shangdi, and Sijiqing residential areas. These high-density buildings and dense population were the main reasons of high LSTs. In addition, the east zone gradually connected and jointly developed with the residential areas in Yanjiao of Hebei province, and the population boom, traffic land extension, and increased vehicle flow together resulted in constantly increasing URI.

4.3. The Impact of the Urban Form on Urban Heat Island. In this study, we compared urban land and URIs in the eight zones at three periods. The results showed that the two indices were in high correlation $\left(R^{2}=0.971\right)$, indicating that the occurrence of UHI effect was likely attributed to the rapid transition from suburban land to urban land (Figure 6). Large-area buildings encroached on more green land, as the 

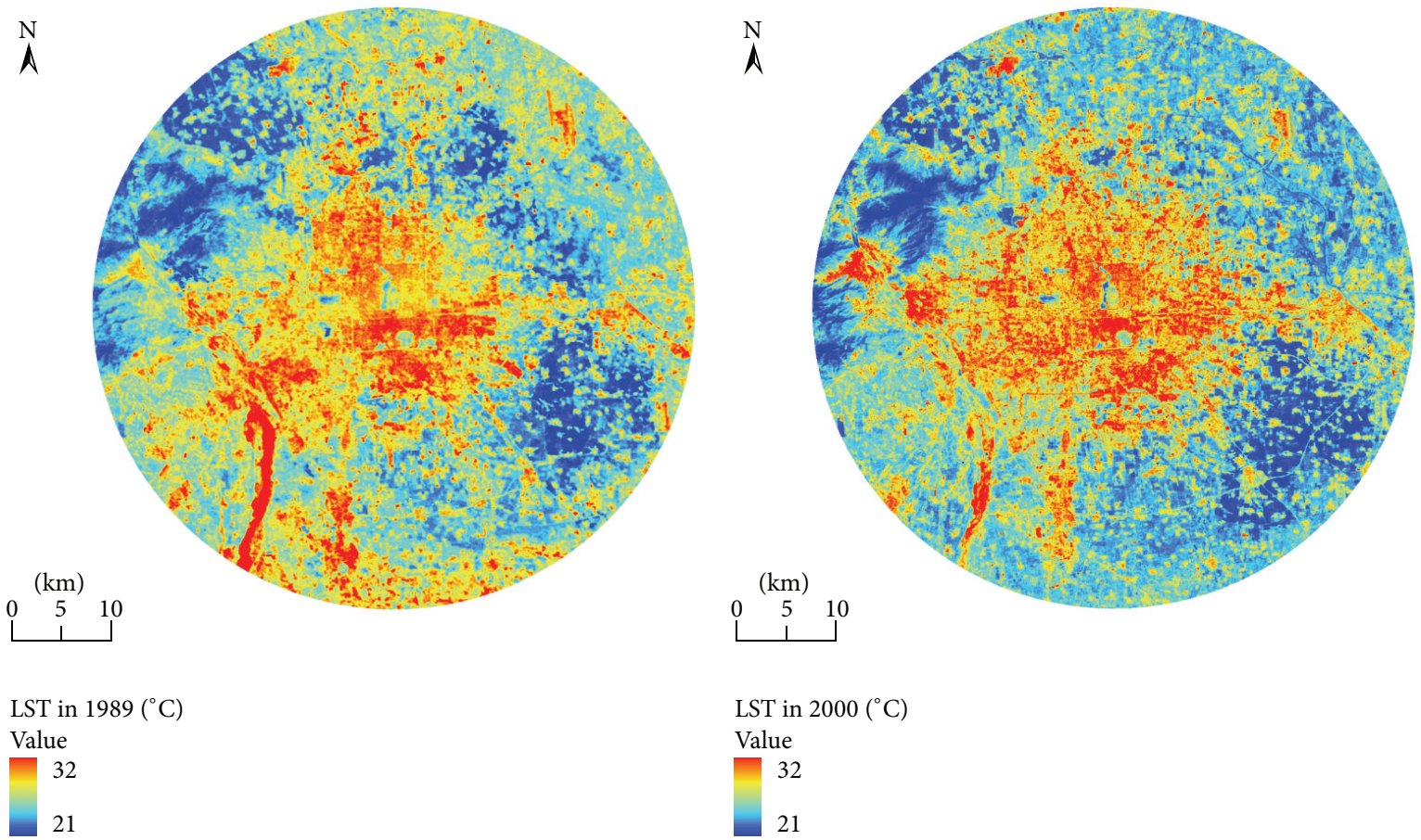

$\begin{array}{ll}\text { (a) LST in } 1989 & \text { (b) LST in } 2000\end{array}$

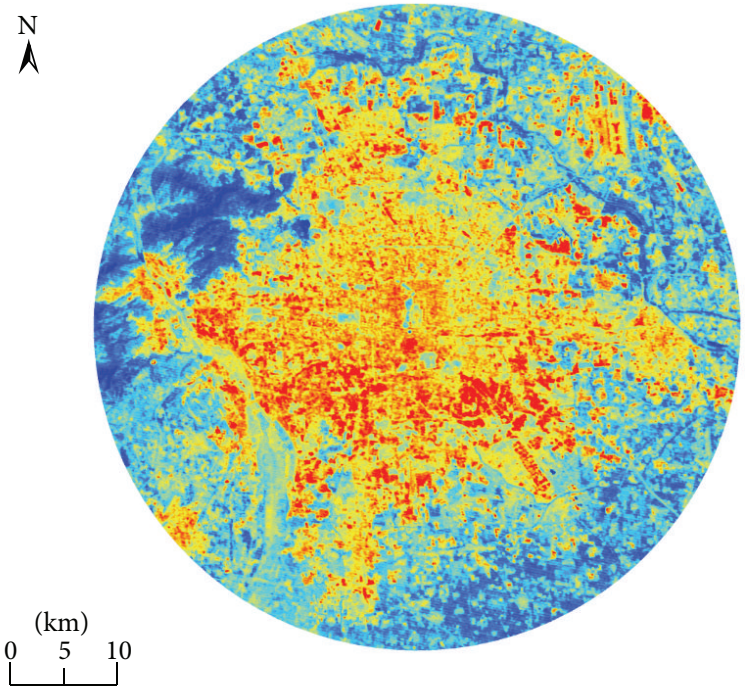

LST in $2010\left({ }^{\circ} \mathrm{C}\right)$
Value
32
21

(c) LST in 2010

FIGURE 4: Spatiotemporal distributions of LST in Beijing.

increase of impervious surface, declines in thermal inertia, and the vegetation index constrain evaporation, consequently reducing the loss of heat by latent heat flux and enhancing UHI effect.

In addition, at the same urban scale, a more compacted urban form indicated more severe UHI. In 1989, the urban lands were nearly identical size (70.17 versus $\left.72.13 \mathrm{~km}^{2}\right)$ in the northeast and west zones of Beijing. However, the BCI was obviously higher in the northeast zone, therefore there was a higher URI, indicating stronger UHI effect in the northeast zone than in the west zone of Beijing. Similarly, the southeast and north zones were equally large (103.09 versus $109.93 \mathrm{~km}^{2}$ ) 


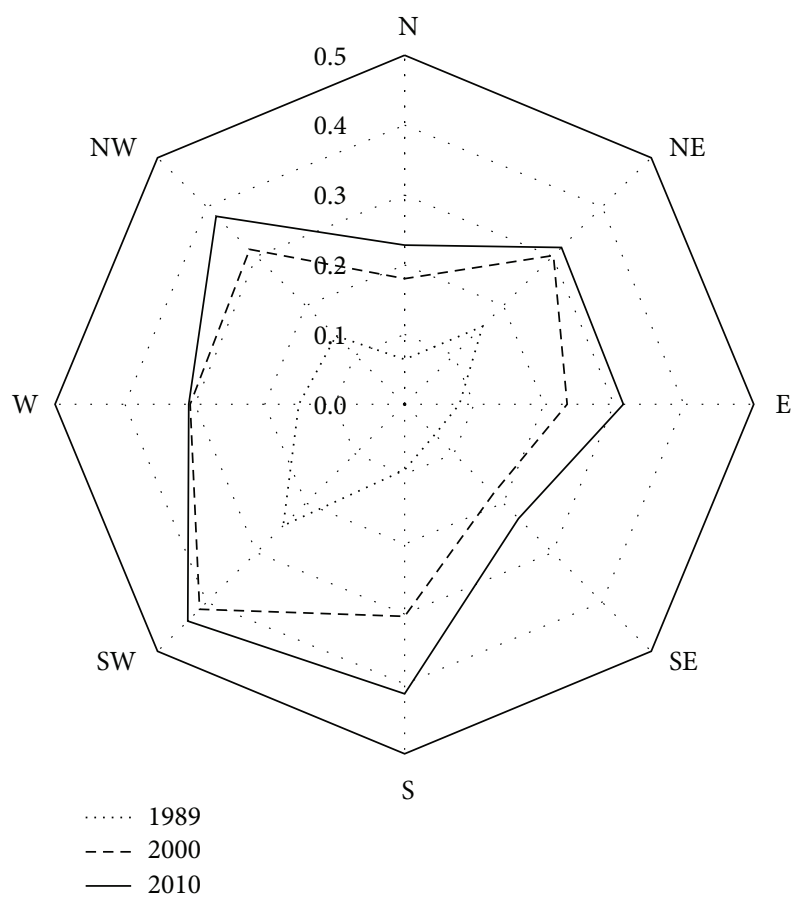

Figure 5: Urban Heat Island Ratio Index.

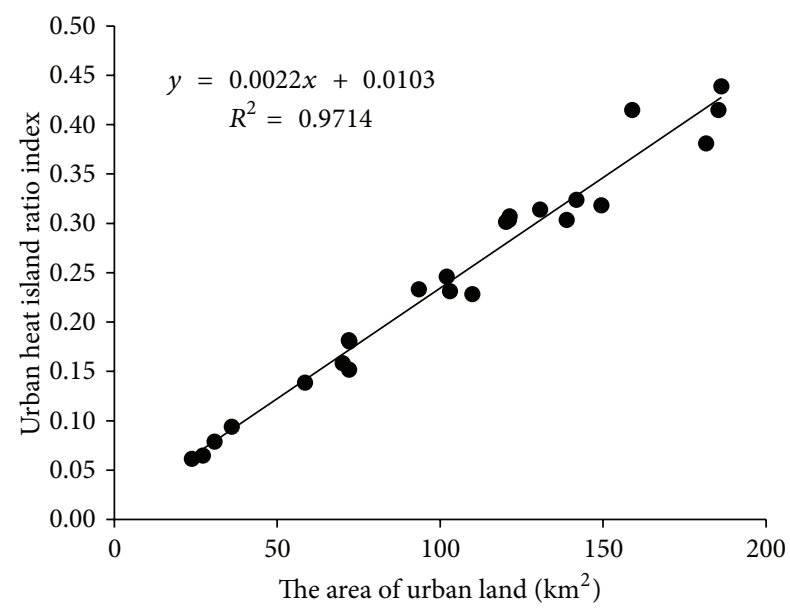

FIGURE 6: The relationship between urban land area and URI.

in 2010; however the urban form was more compacted in the southeast zone, the BCI ( 0.33 versus 0.17 ) and thus URI was higher, indicating stronger UHI effect in the southeast zone than in the north zone. Obviously, higher urban density and surface roughness would weaken the urban-rural air ventilation, blocking the urban internal heat diffusion and increasing the temperature differences between urban area and rural area.

Then the effects of urban land on UHI effect were further analyzed from the aspect of spatial distribution (Figure 7). The gravity centers of urban land generally shifted nearly the edges in all zones between 1989 and 2000, and the gravity center transfer distance was longer during 1989-2000 than during 2000-2010 (Table 4). Gravity center transfer

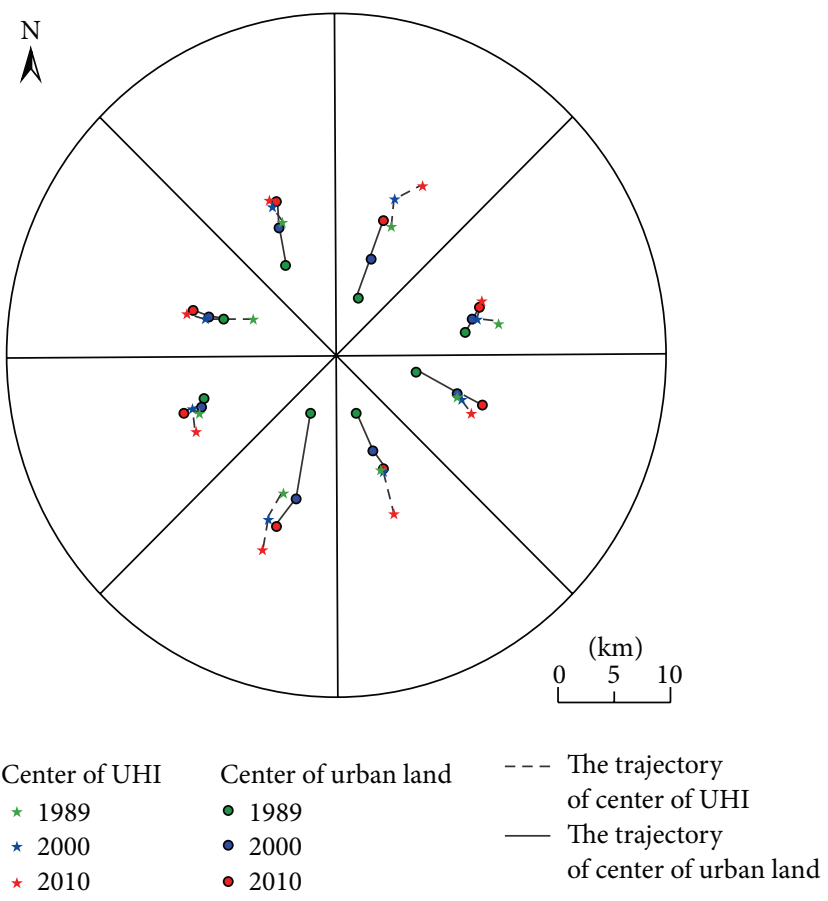

FIGURE 7: Gravity center transfer orbits of urban land and UHI.

in the south zone was more obvious, followed by the east zone, because Fengtai and Daxing Districts in the south zone and Chaoyang District in the east zone experienced the most intense urban land expansion. In the northeast, southwest, and west zones, however, the center transfer distances were shorter between 1989 and 2000 compared with other zones, mainly because the newly urban land in the three zones expanded in an infilling way and thus compactness ratio increased. These results indicated that the expanding intensity and pattern of urban land would largely affect the urban gravity center transfer.

The LSTs in urban land were mainly divided into high and subhigh thermodynamic levels; therefore the two levels were considered as UHI in this paper. The spatial distributions of UHI gravity centers showed that the UHI gravity center was farther away from the city center compared with the gravity center of urban land in the same zone (Figure 7), indicating that the affected area of UHI was greater than urban land. From the aspect of spatial transfer, the gravity centers of UHI and urban land transferred basically in a consistent way and indicated high correlation. Especially in the south zone where urban edge-expansion was more obvious, the gravity centers of UHI and urban land transferred more similarly. However, in the southwest and northeast zones where newly urban land expanded in an infilling way, the gravity center of UHI also transferred irregularly. The encroachment of urban land on the suburb land and a sequence of human activities (e.g., population concentration, increased travel frequency and prolonged trips distance, and industrial restructuring) then resulted in fundamental changes of thermal radiation, heat storage, and heat transfer modes. Therefore, urbanization 
TABLE 4: Gravity center transfer distances and angles of urban land and UHI in 1989-2010 in Beijing.

\begin{tabular}{lcccccccc}
\hline \multirow{2}{*}{ Zones } & \multicolumn{2}{c}{ Urban land } & \multicolumn{2}{c}{ UHI } & \multicolumn{2}{c}{ Urban land } & \multicolumn{2}{c}{$2000-2010$} \\
& Distance & Angle & Distance & Angle & Distance & Angle & Distance & Angle \\
\hline N & 3712.84 & 72.25 & 2398.79 & 74.45 & 3589.19 & 71.21 & 2750.61 & 18.07 \\
NE & 1365.69 & 61.48 & 1998.14 & 163.51 & 1194.50 & 61.22 & 1719.09 & 67.13 \\
E & 4276.40 & 331.52 & 480.08 & 337.33 & 2361.49 & 336.04 & 1483.85 & 296.58 \\
SE & 3731.79 & 294.68 & 309.74 & 328.47 & 1839.50 & 300.80 & 3887.52 & 276.94 \\
S & 7791.64 & 259.82 & 2753.14 & 252.52 & 2998.27 & 234.34 & 2661.15 & 234.30 \\
SW & 773.61 & 254.10 & 660.58 & 331.22 & 1699.14 & 198.00 & 1974.41 & 271.16 \\
W & 1368.30 & 169.64 & 4358.77 & 172.06 & 1499.32 & 159.14 & 1679.55 & 159.58 \\
NW & 3425.77 & 100.07 & 1589.25 & 114.34 & 2329.85 & 95.27 & 693.19 & 108.85 \\
\hline
\end{tabular}

was the most direct and fundamental driving force of the extension of UHI area.

\section{Conclusion}

This study explored the relationship between urban form and UHI through GIS spatial analysis. With the superior spatial resolution of the long time sequenced TM/ETM images, the mechanisms involved in generating UHI resulting from urban form could be recognized.

The urban land increased by $775.82 \mathrm{~km}^{2}$ at a rate of 184.31\% in Beijing during 1989-2010. The urban land distributed like an "E-W" axis in 1989. Urban sprawled in a north-south ward direction in an edge-expansion way in the following two decades, reducing the compactness ratio of urban land. Specifically, the expanding speed index and the expanding intensity slowed down in 2000-2010 than in 1989-2000. The UHIs distributed like an "NE-SW" spindle in Beijing, and the LSTs were obviously higher in the south zone than in the north zone. The LSTs and URIs of urban land in Beijing increased between 1989 and 2010, heat island areas expanded, and the UHI resulting from urban expansion increased obviously.

URI was in high correlation with the urban land area. But at certain urban scale, a more compacted urban form indicated more distinct UHI effect. The gravity centers of $\mathrm{UHI}$ and urban land transferred in a basically consistent way. The UHI effect was attributed to the rapid transition from suburban land to urban land. Expansion of urban land also generated larger UHI area than urban area.

The above discoveries about urban form could be very helpful to alleviate urban thermal environment. Urban planning aims at steering land use changes in urban region by assigning new areas for commercial development and residential land and recovering vegetation. The land use changes will inevitably reshape urban form, which in turn alter urban thermal environment. Therefore, an assessment of urban planning policies with regard to effects on urban climate regulation is useful to further integrate them into spatial planning.

Although the paper explored the impact of urban form on UHI, several topics require further investigations. First, the contributions of water bodies and green land inside the city to the regional LST were not apparent. Increasing greening measures may mitigate UHI effect under the same urban form. Second, the effects of human activities on the urban thermal environment should be investigated to further understand the contributions of urban form to the urban thermal environment.

\section{Conflict of Interests}

The authors declare that there is no conflict of interests regarding the publication of this paper.

\section{Acknowledgments}

This study was supported by National Key Technology R\&D Program of China during the Twelfth Five-Year Plan Period (2012BAC13B01) and the project of National Natural Science Foundation of China under Grant 41071357.

\section{References}

[1] C. Ash, B. R. Jasny, L. Roberts, R. Stone, and A. M. Sugden, "Reimagining cities," Science, vol. 319, no. 5864, p. 739, 2008.

[2] K. Wang, J. Wang, P. Wang, M. Sparrow, J. Yang, and H. Chen, "Influences of urbanization on surface characteristics as derived from the Moderate-Resolution Imaging Spectroradiometer: a case study for the Beijing metropolitan area," Journal of Geophysical Research D: Atmospheres, vol. 112, no. 22, Article ID D22S06, pp. 1-12, 2007.

[3] T. R. Oke, "The energetic basis of the urban heat island," Quarterly Journal of the Royal Meteorological Society, vol. 108, no. 455, pp. 1-24, 1982.

[4] K. P. Gallo, A. L. McNab, T. R. Karl, J. F. Brown, J. J. Hood, and J. D. Tarpley, "The use of a vegetation index for assessment of the urban heat island effect," International Journal of Remote Sensing, vol. 14, no. 11, pp. 2223-2230, 1993.

[5] A. M. Rizwan, L. Y. C. Dennis, and C. Liu, "A review on the generation, determination and mitigation of Urban Heat Island," Journal of Environmental Sciences, vol. 20, no. 1, pp. 120128, 2008.

[6] F. Yuan and M. E. Bauer, "Comparison of impervious surface area and normalized difference vegetation index as indicators of surface urban heat island effects in Landsat imagery," Remote Sensing of Environment, vol. 106, no. 3, pp. 375-386, 2007. 
[7] T. R. Oke, "The urban energy balance," Progress in Physical Geography, vol. 12, no. 4, pp. 471-508, 1988.

[8] J. A. Voogt and T. R. Oke, "Thermal remote sensing of urban climates," Remote Sensing of Environment, vol. 86, no. 3, pp. 370384, 2003.

[9] X.-L. Chen, H.-M. Zhao, P.-X. Li, and Z.-Y. Yin, "Remote sensing image-based analysis of the relationship between urban heat island and land use/cover changes," Remote Sensing of Environment, vol. 104, no. 2, pp. 133-146, 2006.

[10] U. W. Tang and Z. S. Wang, "Influences of urban forms on traffic-induced noise and air pollution: results from a modelling system," Environmental Modelling and Software, vol. 22, no. 12, pp. 1750-1764, 2007.

[11] Y. Liu, Y. Song, and H. P. Arp, "Examination of the relationship between urban form and urban eco-efficiency in China," Habitat International, vol. 36, no. 1, pp. 171-177, 2012.

[12] T. R. Oke, "City size and the urban heat island," Atmospheric Environment, vol. 7, no. 8, pp. 769-779, 1973.

[13] A. Kondoh and J. Nishiyama, "Changes in hydrological cycle due to urbanization in the suburb of Tokyo Metropolitan area, Japan," Advances in Space Research, vol. 26, no. 7, pp. 1173-1176, 2000.

[14] A. Christen and R. Vogt, "Energy and radiation balance of a central European City," International Journal of Climatology, vol. 24, no. 11, pp. 1395-1421, 2004.

[15] M. Breheny, Sustainable Development and Urban Form, Pion Limited, London, UK, 1992.

[16] G. de Roo and D. Miller, Compact Cities and Sustainable Urban Development: A Critical Assessment of Policies and Plans from an International Perspective, Ashgate, Aldershot, UK, 2000.

[17] R. Ewing, "Is Los Angeles-style sprawl desirable?" Journal of the American Planning Association, vol. 63, no. 1, pp. 107-126, 1997.

[18] J. K. Brueckner, "Urban sprawl: diagnosis and remedies," International Regional Science Review, vol. 23, no. 2, pp. 160-171, 2000.

[19] M. P. Johnson, "Environmental impacts of urban sprawl: a survey of the literature and proposed research agenda," Environment and Planning A, vol. 33, no. 4, pp. 717-735, 2001.

[20] M. Breheny, "The compact city and transport energy consumption," Transactions of the Institute of British Geographers, vol. 20, no. 1, pp. 81-101, 1995.

[21] O. Mindali, A. Raveh, and I. Salomon, "Urban density and energy consumption: a new look at old statistics," Transportation Research A, vol. 38, no. 2, pp. 143-162, 2004.

[22] P. Rickwood, G. Glazebrook, and G. Searle, "Urban structure and energy-a review," Urban Policy and Research, vol. 26, no. 1, pp. 57-81, 2008.

[23] L. O. Marquez and N. C. Smith, "A framework for linking urban form and air quality," Environmental Modelling and Software, vol. 14, no. 6, pp. 541-548, 1999.

[24] J. Huang, X. X. Lu, and J. M. Sellers, "A global comparative analysis of urban form: applying spatial metrics and remote sensing," Landscape and Urban Planning, vol. 82, no. 4, pp. 184197, 2007.

[25] M. Batty, "New ways of looking at cities," Nature, vol. 377, no. 6550, p. 574, 1995.

[26] P. Frankhauser, "The fractal approach. A new tool for the spatial analysis of urban agglomerations," Population, vol. 52, no. 4, pp. 1005-1040, 1997.
[27] Y. Chen, "Derivation of the functional relations between fractal dimension of and shape indices of urban form," Computers, Environment and Urban Systems, vol. 35, no. 6, pp. 442-451, 2011.

[28] H. Q. Xu and B. Q. Chen, "An image processing technique for the study of urban heat island changes using different seasonal remote sensing data," Remote Sensing Technology and Application, vol. 18, no. 3, pp. 129-133, 2003 (Chinese).

[29] S. Xu, "An approach to analyzing the intensity of the daytime surface urban heat island effect at a local scale," Environmental Monitoring and Assessment, vol. 151, no. 1-4, pp. 289-300, 2009.

[30] Z. Qiao, G. J. Tian, and L. Xiao, "Diurnal and seasonal impacts of urbanization on the urban thermal environment: a case study of Beijing using MODIS data," Journal of Photogrammetry and Remote Sensing, vol. 85, pp. 93-101, 2013.

[31] K. P. Gallo and T. W. Owen, "Assessment of urban heat islands: a multi-sensor perspective for the Dallas-Ft. Worth, USA region," Geocarto International, vol. 13, no. 4, pp. 35-41, 1998.

[32] D. R. Streutker, "A remote sensing study of the urban heat island of Houston, Texas," International Journal of Remote Sensing, vol. 23, no. 13, pp. 2595-2608, 2002.

[33] Q. Weng, "A remote sensing-GIS evaluation of urban expansion and its impact on surface temperature in the Zhujiang Delta, China," International Journal of Remote Sensing, vol. 22, no. 10, pp. 1999-2014, 2001.

[34] J. Nichol and M. S. Wong, "Modeling urban environmental quality in a tropical city," Landscape and Urban Planning, vol. 73, no. 1, pp. 49-58, 2005.

[35] Beijing Statistics Bureau, Beijing StatisticalYearbook 2010, China Statistics Press, Beijing, China, 2010.

[36] X. A. Xia, H. B. Chen, P. C. Wang et al., "Variation of columnintegrated aerosol properties in a Chinese urban region," Journal of Geophysical Research D: Atmospheres, vol. 111, no. 5, Article ID D05204, 2006.

[37] J. Zhang, Y. Hou, G. Li, H. Yan, L. Yang, and F. Yao, “The diurnal and seasonal characteristics of urban heat island variation in Beijing city and surrounding areas and impact factors based on remote sensing satellite data," Science in China D: Earth Sciences, vol. 48, no. 2, pp. 220-229, 2005 (Chinese).

[38] Q. S. Ge, J. H. Dai, J. Liu, S. Y. Zhong, and H. T. Liu, “The effect of climate change on the fall foliage vacation in China," Tourism Management, vol. 38, pp. 80-84, 2013.

[39] J. Liu, M. Liu, H. Tian et al., "Spatial and temporal patterns of China's cropland during 1990-2000: an analysis based on Landsat TM data," Remote Sensing of Environment, vol. 98, no. 4, pp. 442-456, 2005.

[40] P. Haggett, A. D. Cliff, and A. Frey, Locational Analysis in Human Geography, Edward Arnold, London, UK, 2nd edition, 1977.

[41] B. Y. Lin, "The calculation method of urban spatial form and its evaluation," Urban Planning Forum, vol. 21, no. 3, pp. 42-45, 1998 (Chinese).

[42] X. Wang, J. Liu, D. Zhuang, and L. Wang, "Spatial-temporal changes of urban spatial morphology in China," Acta Geographica Sinica, vol. 60, no. 3, pp. 392-400, 2005 (Chinese).

[43] P. S. Nivola, Laws of the Landscape: How Policies Shape Cities in Europe and America, Brookings Institution Press, Washington, DC, USA, 1999.

[44] F. Dieleman and M. Wegener, "Compact city and urban sprawl," Built Environment, vol. 30, no. 4, pp. 308-323, 2004. 
[45] J. Y. Liu and H. Bu, "Study on spatial-temporal feature of modern land-use change in China: using remote sensing techniques," Quaternary Sciences, vol. 20, no. 3, pp. 229-239, 2000 (Chinese).

[46] H.-Q. Xu and B.-Q. Chen, "Remote sensing of the urban heat island and its changes in Xiamen City of SE China," Journal of Environmental Sciences, vol. 16, no. 2, pp. 276-281, 2004.

[47] J. H. Xu, C. L. Fang, and W. Z. Yue, "An analysis of the mosaic structure of regional landscape using GIS and remote sensing," Acta Ecologica Sinica, vol. 23, no. 2, pp. 365-375, 2003 (Chinese).

[48] S. Q. Zhang, J. Y. Zhang, and F. Li, "Vector analysis theory on landscape pattern in Sanjiang plain marsh, China," Wetland Science, vol. 9, no. 3, pp. 161-170, 2004.

[49] W. Kuang, S. Zhang, Y. Zhang, and Y. Sheng, "Analysis of urban land utilization spatial expansion mechanism in Changchun city since 1900," Acta Geographica Sinica, vol. 60, no. 5, pp. 841850, 2005 (Chinese).

[50] Y. H. Chen, J. Wang, and X. B. Li, "A study on urban thermal field in summer based on satellite remote sensing," Remote Sensing for Land and Resources, vol. 14, no. 4, pp. 55-59, 2002.

[51] J. E. Nichol, "A GIS-based approach to microclimate monitoring in Singapore's high- rise housing estates," Photogrammetric Engineering \& Remote Sensing, vol. 60, no. 10, pp. 1225-1232, 1994.

[52] D. A. Artis and W. H. Carnahan, "Survey of emissivity variability in thermography of urban areas," Remote Sensing of Environment, vol. 12, no. 4, pp. 313-329, 1982.

[53] Q. Weng, "Fractal analysis of satellite-detected urban heat island effect," Photogrammetric Engineering \& Remote Sensing, vol. 69, no. 5, pp. 555-566, 2003.

[54] Q. Weng, D. Lu, and J. Schubring, "Estimation of land surface temperature-vegetation abundance relationship for urban heat island studies," Remote Sensing of Environment, vol. 89, no. 4, pp. 467-483, 2004.

[55] Q. Weng and S. Yang, "Managing the adverse thermal effects of urban development in a densely populated Chinese city," Journal of Environmental Management, vol. 70, no. 2, pp. 145156, 2004.

[56] Q. Weng and S. Yang, "Urban air pollution patterns, land use, and thermal landscape: an examination of the linkage using GIS," Environmental Monitoring and Assessment, vol. 117, no. 13, pp. 463-489, 2006.

[57] Q. Weng, "Thermal infrared remote sensing for urban climate and environmental studies: methods, applications, and trends," ISPRS Journal of Photogrammetry and Remote Sensing, vol. 64, no. 4, pp. 335-344, 2009.

[58] T. W. Hawkins, A. J. Brazel, W. L. Stefanov, W. Bigler, and E. M. Saffell, "The role of rural variability in urban heat island determination for Phoenix, Arizona," Journal of Applied Meteorology, vol. 43, no. 3, pp. 476-486, 2004. 

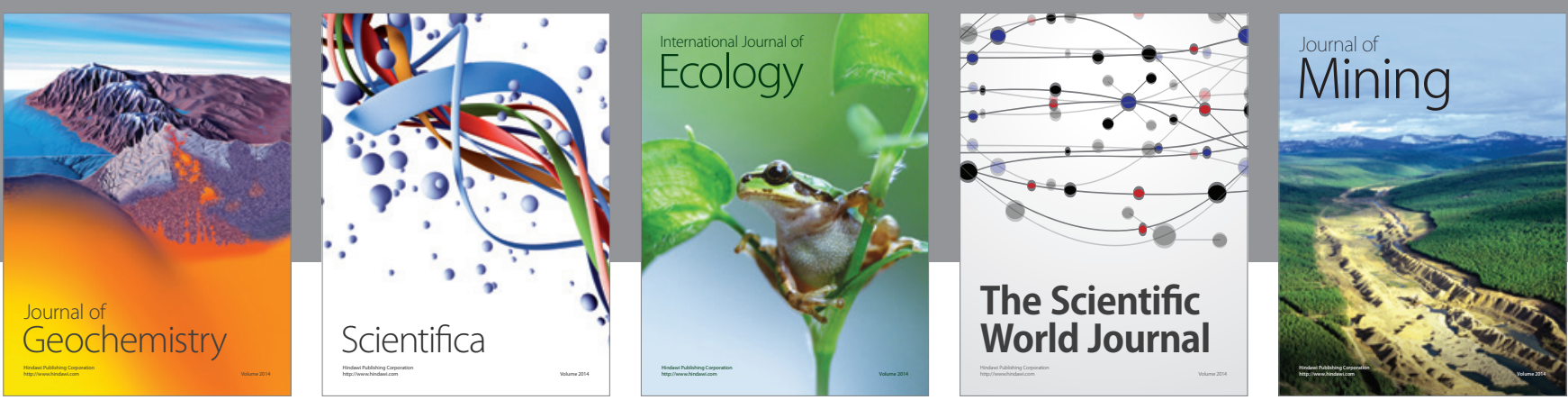

The Scientific World Journal
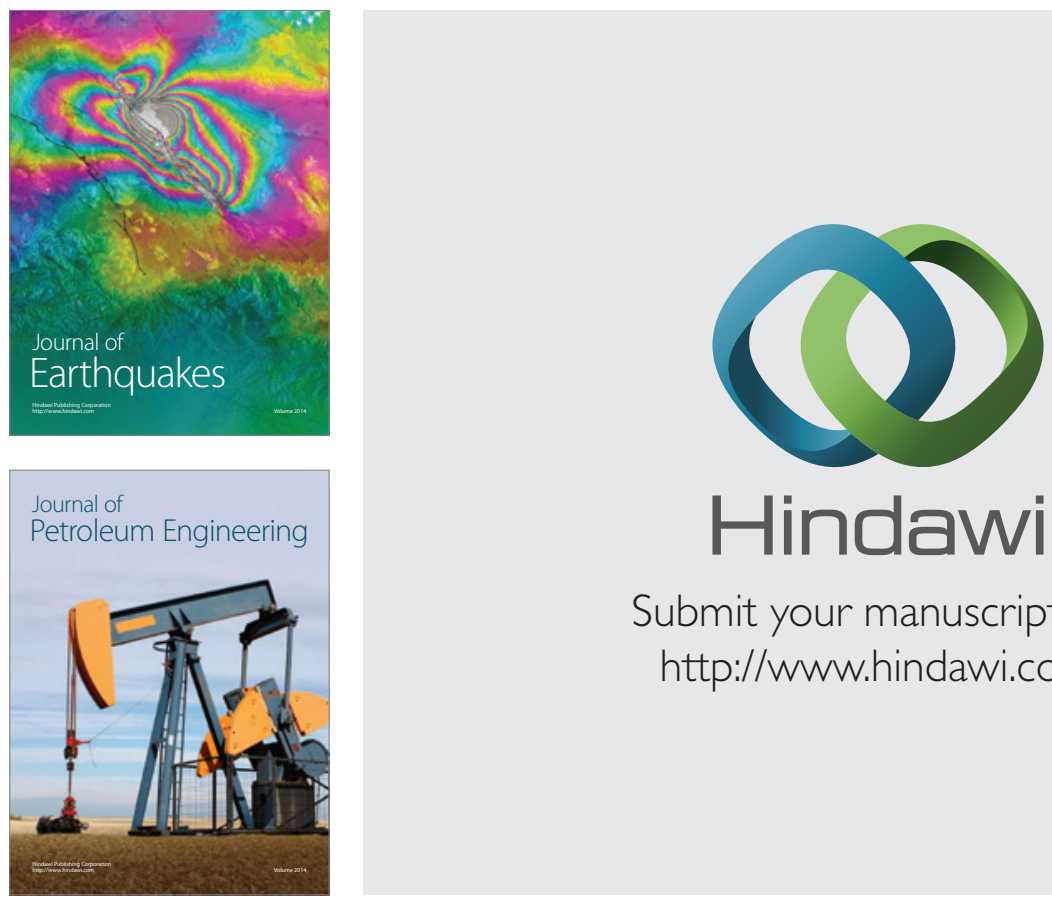

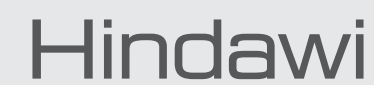

Submit your manuscripts at

http://www.hindawi.com
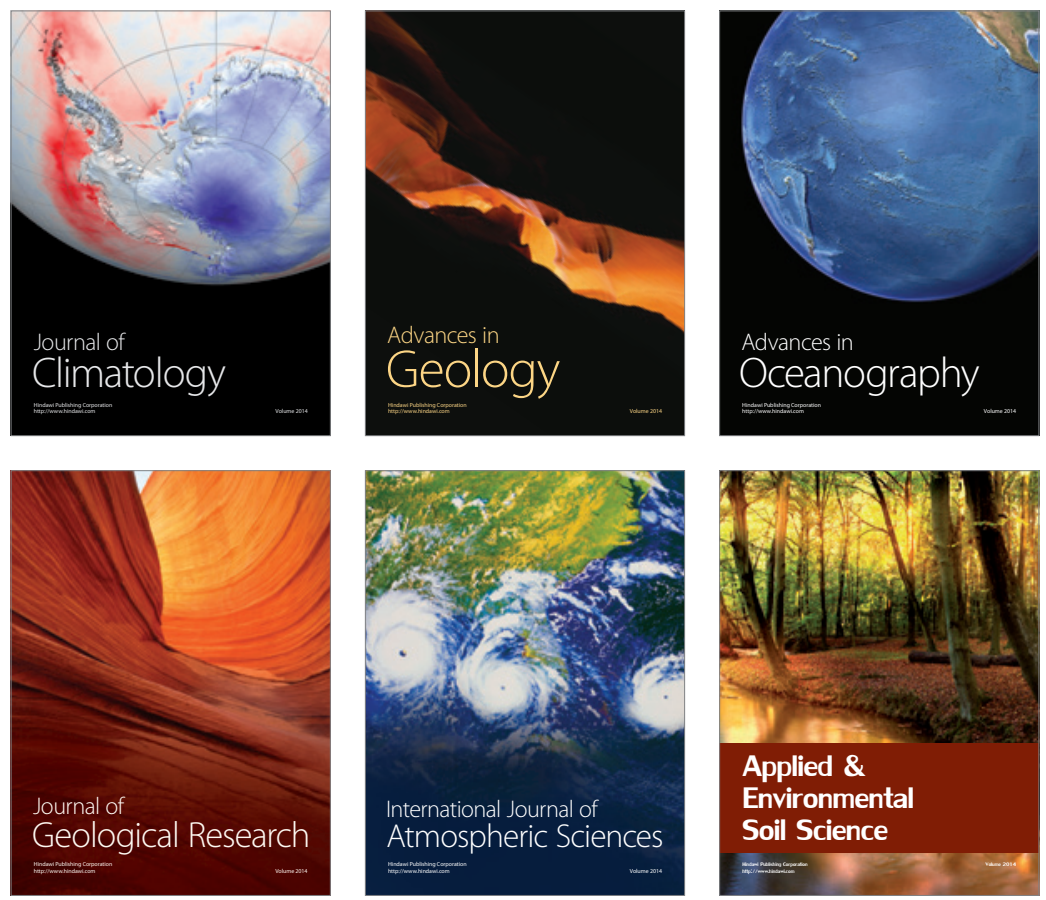
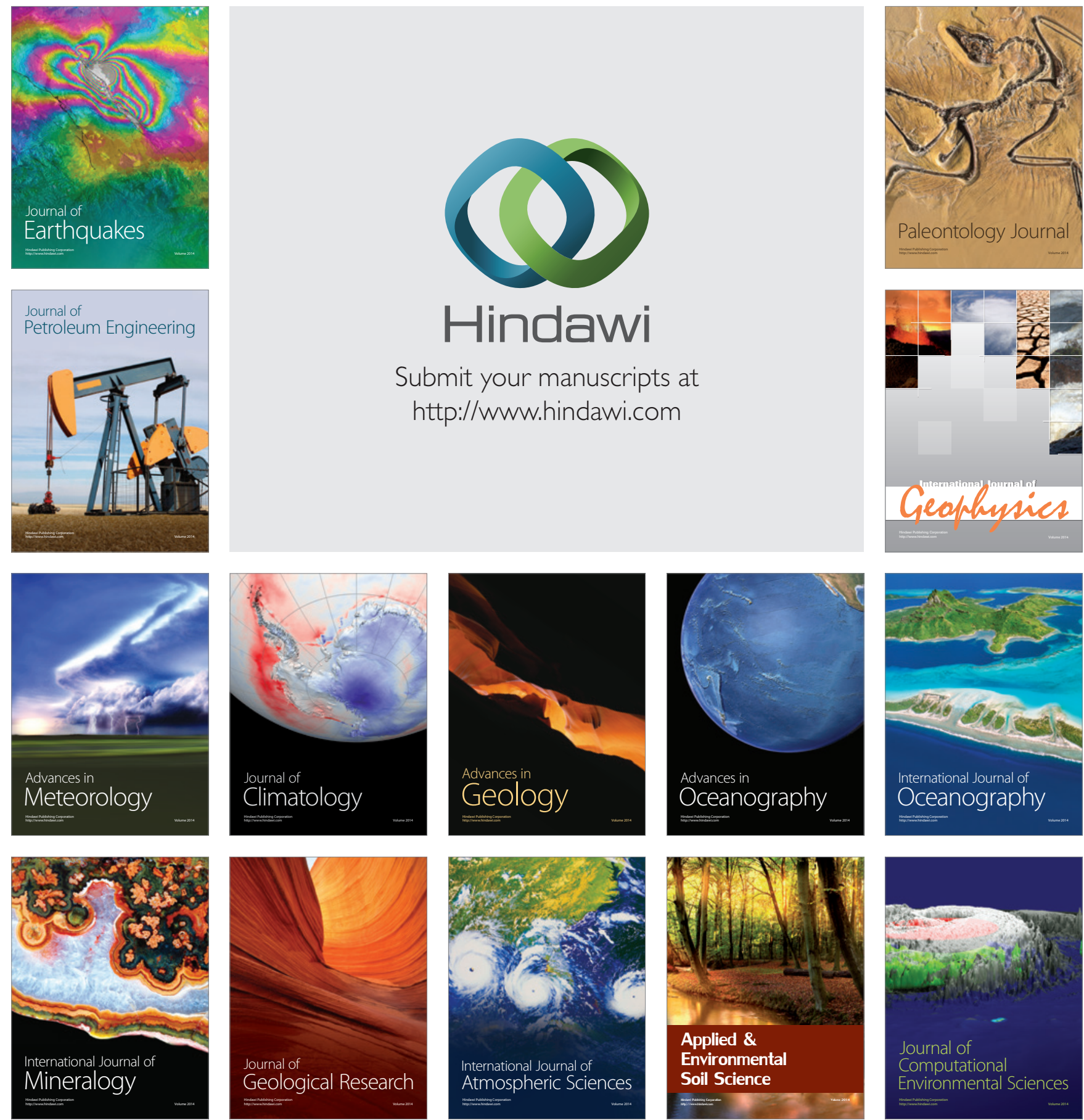